\title{
АССОРТАТИВНОСТЬ БРАКОВ ПО УРОВНЮ \\ ОБРАЗОВАНИЯ: ИЗМЕНЕНИЯ В СВЯЗИ С ЭКСПАНСИЕЙ ВЫСШЕГО ОБРАЗОВАНИЯ В РОССИИ
}

\author{
ДАРЬЯ ЗИНЧЕНКО
}

\begin{abstract}
Работа посвящена изучению связи между охватом высшим образованием, динамикой его расширения, усилением гендерного дисбаланса в образовательной структуре населения и брачным поведением мужчин и женщин. Для анализа использованы несколько взаимодополняющих источников данных: РМЭЗ ВШЭ (Российский мониторинг экономического положения и здоровья населения НИУ ВШЭ), Обследование рабочей силь и расчетные данные Росстата о численности постоянного населения за 1995-2015 г2. При построении мультиномиальной логистической модели эффект образования мы рассматриваем как на микроуровне (в качестве индивидуальной характеристики человека), так и на макроуровне (в терминах сочиально-демографических структур региональных брачных рынков). Проведенный анализ показал, что для мужчин получение высшего образования увеличивает вероятность состоять в браке, а для женщин - не снижает ее. Региональные характеристики слабо коррелируют с брачным статусом мужчин и женщин, но оказывают значимое воздействие на ассортативность браков. Среди женского населения гендерный дисбаланс в образовательной структуре населения в пользу является важным фактором распространения эгалитарного паттерна избирательности, в котором муж менее образован, чем жена. Мужчинь на усиление образовательного дисбаланса в пользу женщин реагируют так же, как и женская часть населения, но с противоположным знаком. Они смещают предпочтения от брака, в котором жена имеет такой же уровень образования, в пользу союза с более образованной партнершей, потенциильно имеющей более высокие доходы. Охват высшим образованием населения региона сказывается только на избирательности браков мужчин: снижает вероятность союза с менее образованной женщиной. Ассортативность браков для обоих полов не зависит от темпов экспансии высшего образования.
\end{abstract}

Ключевые слова: высшее образование, брачное поведение, ассортативность браков, гендер, брачный рынок.

\section{ВВЕДЕНИЕ}

Начиная со второй половины XX века мир включился в образовательную гонку, которая выражается в постоянном увеличении доли населения с третичным, прежде всего высшим, уровнем образования (Schofer, Meyer 2005). Рост охвата высшим образованием не был гендерно нейтральным: женщины оказались более активно вовлечены в этот процесс. В развитых странах образовательные структуры мужчин и женщин начали сближаться с 1960-х годов, а в 1990-е доля имеющих высшее образование среди женщин превысила соответствующий показатель среди мужчин (Esteve et al. 2016).

ДАРЬЯ ИГОРЕВНА ЗИНЧЕНКО (dzinchenko@hse.ru), НАЦИОНАЛЬНЫЙ ИССЛЕДОВАТЕЛЬСКИЙ УНИВЕРСИТЕТ «ВЫСШАЯ ШКОЛА ЭКОНОМИкИ», РОсСия.

ИССЛЕДОВАНИЕ ВЫПОЛНЕНО ПРИ ФИНАНСОВОЙ ПОДДЕРЖКЕ РФФИ В РАМКАХ НАУЧНОГО ПРОЕКТА № 19-310-90071.

СТАТЬЯ ПОСТУПИЛА В РЕДАКЦИЮ В ИЮЛЕ 2021 Г. 
Россия является одним из лидеров образовательного апгрейдинга. По данным переписей, с 1989 по 2015 г. доля лиц с высшим образованием среди населения 15 лет и старше выросла с 11,3 до 25,8\% (Итоги Всесоюзной... 1989; Росстат 2015). При этом в России перелом в структуре образования в пользу женщин произошел значительно раньше, чем в других странах: уже в начале 1970-х годов девушки составляли больше половины студентов вузов (Бессуднов, Куракин, Малик 2017).

Экспансия высшего образования и гендерные различия в уровне образования отражаются на демографическом поведении населения, в том числе на решениях о вступлении в брак и выборе брачного партнера. Исторически получение высшего образования оказывало разное влияние на мужчин и женщин. Для мужчин получение высшего образования являлось важным преимуществом на брачном рынке как потенциальный источник высоких доходов (Becker 1991). Для женщин высшее образование, хотя и означало большую независимость и финансовую самостоятельность, но снижало привлекательность на брачном рынке и вело к сокращению шансов выйти замуж на протяжении всей жизни (Goldin, Katz, Kuziemko 2006). В последние десятилетия в этом отношении происходят важные перемены. Во многих развитых странах получение женщиной высшего образования увеличивает вероятность вступить в брак (хотя и в более позднем возрасте), снижает риски развода, а в случае развода повышает шансы на повторный брак (Schwartz, Han 2014). Наоборот, женщины с низким уровнем образования вступают в брак - зачастую незарегистрированный - в более раннем возрасте, однако их отношения чаще заканчиваются разрывом, поэтому значительную часть взрослой жизни они проводят без партнера (Oppenheimer 1997; Isen, Stevenson 2010). Менее позитивная картина складывается в странах с высоким уровнем гендерной сегрегации, где опережающий рост образования среди женщин по-прежнему не дает дополнительных преимуществ на брачном рынке (Kalmijn 2013; Bertrand et al. 2016). Результаты предшествующих исследований по России можно интерпретировать в том смысле, что Россия занимает промежуточное или переходное положение на пути демографической модернизации в части брачного поведения. В советское время в начале 1980-х годов различия в доле состоящих в браке среди мужчин, имеющих образование выше неполного среднего, были малозаметны, тогда как среди женщин с высшим образованием наблюдалась самая высокая доля остающихся вне брака (Дарский, Ильина 2000). С распадом СССР брачные паттерны поведения людей начали модернизироваться. И уже в современной России среди мужчин с высшим образованием доля состоящих в браке стала заметно выше, чем среди тех, кто имеет более низкий уровень образования. Среди женщин высшее образование перестало влиять на вероятность состоять в браке: доля замужних женщин ощутимо ниже лишь в группе с образованием ниже среднего (Perelli-Harris, LyonsAmos 2016; Зинченко, Лукьянова 2021).

Рост уровня образования оказал влияние и на образовательную избирательность браков. Экономисты считают, что со второй половины прошлого столетия, благодаря масштабным социальным сдвигам, образование начинает приносить отдачу не только на рынке труда, но и на брачном рынке, причем не только мужчинам, но и женщинам (Chiappori, Iyigun, Weiss 2009). На рынке труда более высокий уровень образования обеспечивает более высокие заработки. На брачном рынке высокий образовательный 
уровень способствует браку с более «качественным» кандидатом, что увеличивает семейный бюджет - данное обстоятельство становится все более значимым по мере распространения модели семьи с двумя занятыми. Социологи также фиксируют, что экспансия высшего образования ведет к увеличению влияния образовательной системы на брачное поведение и к усилению ее структурного воздействия на избирательность браков. Молодые люди остаются в системе образования все дольше и именно в тех возрастах, когда поиск партнера наиболее интенсивен и число свободных партнеров максимально. В учебных заведениях они попадают в среду, снижающую издержки поиска и многократно повышающую шансы встретить потенциального партнера с тем же уровнем образования (Blossfeld, Timm 2003; Nielsen, Svarer 2009).

Гендерная асимметрия в уровне образования имеет самостоятельное влияние на брачное поведение. Повышение образовательного уровня женщин по сравнению с мужчинами сопровождается постепенным сближением предпочтений мужчин и женщин в отношении желаемых характеристик партнеров и увеличением доли браков, в которых оба супруга имеют одинаковый уровень образования (гомогамия). Одновременно уменьшается образовательная гипергамия (доля пар, в которых муж более образован, чем жена) и увеличивается гипогамия (доля пар, в которых муж менее образован, чем жена) (Schwartz, Mare 2005; Esteve et al. 2016). Впрочем, многие исследователи признают, что ключевую роль в формировании наблюдаемых трендов играют изменения в сфере образования, а не в предпочтениях в отношении образования супруга(-и) (Gihleb, Lang 2020).

В России и мужчины, и женщины также склонны выбирать партнера, имеющего тот же уровень образования (Волков 1986; Рощина, Рощин 2008; Зинченко, Лукьянова 2018). Как и в развитых странах, в последние десятилетия в России происходило увеличение гипогамии. Однако в отличие от развитых стран, распространение гипогамных браков происходило не за счет снижения гипергамии, а за счет сокращения гомогамии. Рост гипогамии был обусловлен главным образом изменениями в образовательной структуре населения, существенного увеличения склонности к гипогамным бракам не происходило даже в молодых возрастах (Зинченко, Лукьянова 2021). Таким образом, гендерные нормы в сфере брака меняются значительно медленнее, чем в сфере образования.

В фокусе данной работы - брачное поведение на фоне экспансии высшего образования. Мы анализируем эту связь с учетом гендерной, возрастной и региональной неравномерности происходящих изменений в сфере образования. Эффект образования рассматривается на двух уровнях: на индивидуальном и как фактор внешнего окружения. На индивидуальном уровне мы исследуем, как наличие того или иного уровня образования влияет на вероятность состоять в браке и на выбор партнера с определенным образовательным статусом. Одновременно мы учитываем, что эти взаимосвязи могли меняться под воздействием образования как экзогенного фактора, т. е. вследствие роста охвата населения высшим образованием и усиления гендерной асимметрии в образовательной структуре окружения индивида. 


\section{ОПИСАНИЕ ДАННЫХ РМЭЗ ВШЭ}

Для анализа образовательной ассортативности браков мы использовали данные Российского мониторинга экономического положения и здоровья населения НИУ ВШЭ (РМЭЗ ВШЭ), проводимого Национальным исследовательским университетом «Высшая школа экономики» и ООО «Демоскоп» при участии Центра народонаселения Университета Северной Каролины в Чапел Хилле и Института социологии РАН) ${ }^{1}$, за 1995-2015 гг. Для формирования переменных регионального брачного рынка дополнительно брали данные выборочного Обследования рабочей силы (ОРС), проводимого Росстатом, и расчетные данные Росстата о численности постоянного населения по полу и возрасту на начало года.

Весь анализ проводили по репрезентативной части выборки РМЭЗ ВШЭ. Выборка ограничена индивидами в возрасте 30-50 лет с полной информацией по полу, возрасту и уровню образования. Выбор этого возрастного интервала позволяет, с одной стороны, минимизировать влияние увеличения возраста вступления в брак, с другой - исключить старшие группы, мало затронутые экспансией высшего образования в 1990-2000-е годы. Выборка включает как состоящих, так и не состоящих в браке. Мы не проводили различий между зарегистрированными браками и незарегистрированными партнерскими союзами. Наличие партнерских отношений устанавливали на основе семейного вопросника РМЭЗ ВШЭ. Дизайн обследования позволяет учесть только те пары, которые проживают совместно в одном домохозяйстве. Поэтому те индивиды, которые не проживают в одном домохозяйстве с партнером, были отнесены к не состоящим в браке. Не состоящие в браке также включают никогда не состоявших в браке, разошедшихся, разведенных и вдовых. Заметим, что наблюдаемая брачная ситуация складывается под воздействием разных процессов: первичных браков, разводов, повторных браков и получения образования в период нахождения в браке.

На рисунке 1 показано, как изменилась образовательная структура населения за рассматриваемые 20 лет. Гендерная асимметрия в образовании в пользу женщин наблюдалась уже в середине 1990-х годов. В этот период она отмечалась прежде всего на уровне среднего профессионального образования, тогда как среди мужчин значительно выше была доля обладателей общего среднего образования. Со временем гендерный разрыв сместился в сферу высшего образования. За 1995-2015 гг. представленность лиц с высшим образованием среди женщин увеличилась в 1,6 раза и составила $36 \%$, тогда как доля мужчин с высшим образованием выросла гораздо скромнее - с 20 до 24\%. Гендерный разрыв в охвате высшим образованием увеличился с 2 до 12 п.п., но сократился в 2 раза в охвате средним профессиональным образованием. Среди мужчин по-прежнему выше доля тех, чье формальное образование завершилось окончанием средней школы. При этом доля обладателей среднего образования сокращалась для обоих полов равномерно, сохранив разрыв на уровне 13 п.п. Вместе с тем наблюдалось увеличение доли тех,

\footnotetext{
${ }^{1}$ Сайты обследования РМЭЗ ВШЭ: http://www.cpc.unc.edu/projects/rlms и http://www.hse.ru/rlms.
} 
чье образование ниже среднего ${ }^{2}$. К 2015 г. их доля составила $15 \%$ среди мужчин и 9\% среди женщин.

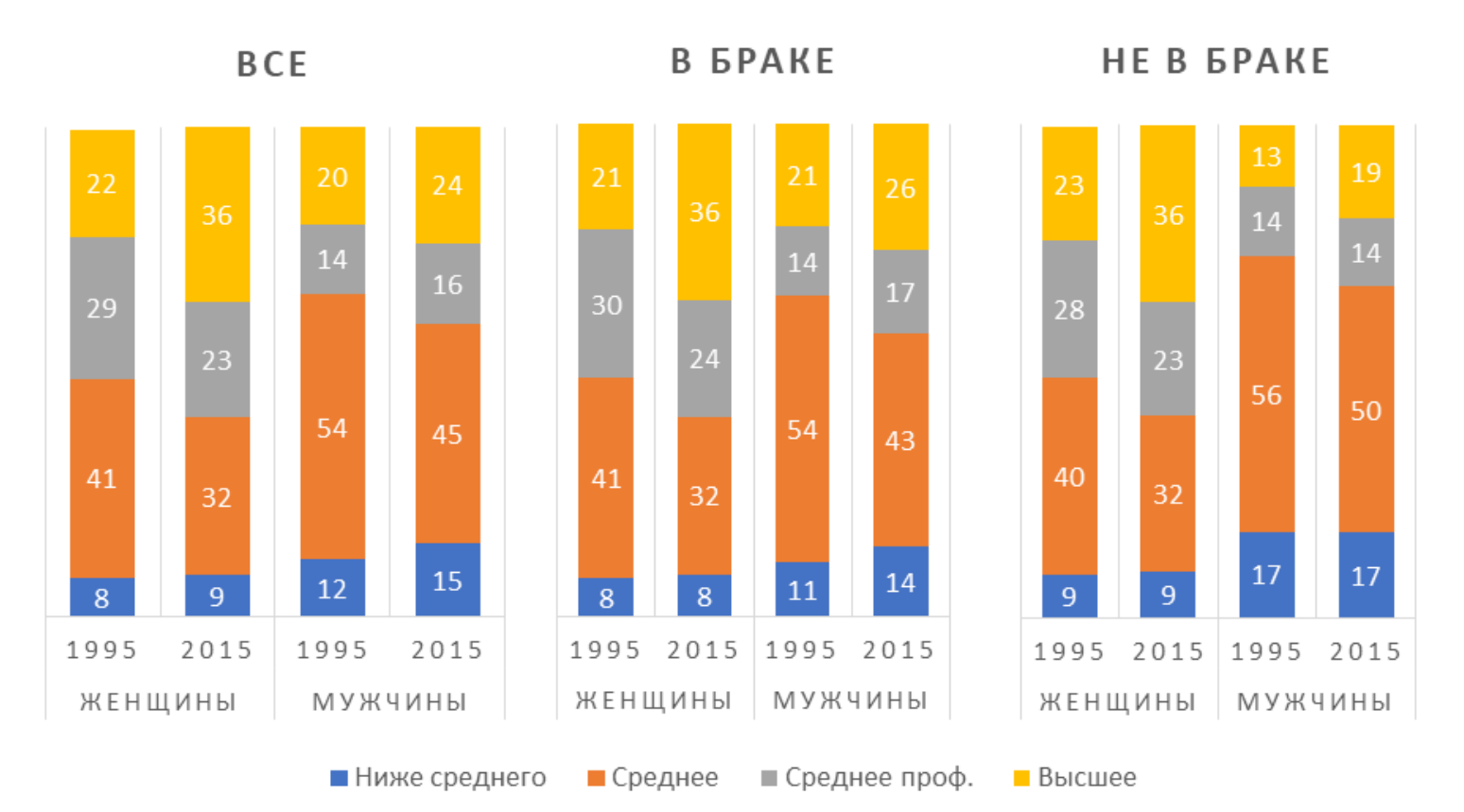

\section{Рисунок 1. Распределение населения в возрасте 30-50 лет по уровню образования}

Источник: Расчеты автора по данным РМЭЗ ВШЭ.

На рисунке 1 видно, что мужчины, не состоящие в браке, в среднем имеют более низкий уровень образования по сравнению с женатыми мужчинами, тогда как образовательные структуры замужних и одиноких женщин практически совпадают. Сдвиги в образовательной структуре населения, состоящего и не состоящего в браке, оказались схожими, особенно среди женщин. Независимо от брачного статуса устойчиво рос удельный вес лиц с высшим образованием и среди женщин быстрее, чем среди мужчин.

\section{ДЕСКРИПТИВНЫЙ АНАЛИЗ ИЗМЕНЕНИЙ БРАЧНОГО СТАТУСА И ИЗБИРАТЕЛЬНОСТИ БРАКОВ ПО УРОВНЮ ОБРАЗОВАНИЯ}

Сокращение доли лиц, состоящих в браке, затронуло представителей обоих полов (рисунок 2). У мужчин это сокращение имело постоянно нисходящий тренд. У женщин сокращение доли состоящих в браке не было непрерывным: оно происходило вплоть до конца 2000-х годов, а затем сменилось небольшим ростом ${ }^{3}$. У женщин общее сокращение доли состоящих в браке составило 7 п.п. (с 77\% в 1995 г. до 70\% в 2015 г.), у мужчин - 9 п.п. (с 88 до 79\%). Доля замужних и женатых уменьшалась прежде всего за счет увеличения

\footnotetext{
2 В эту группу включены и все лица, закончившие ПТУ на базе неполного среднего образования.

${ }^{3}$ В целом результаты, полученные по РМЭЗ ВШЭ, сходны с данными переписей. Несмотря на то, что оценки доли состоящих в браке в данных РМЭЗ ВШЭ несколько выше, общие тенденции в этих обследованиях совпадают. Завышенные оценки доли состоящих в браке в РМЭЗ ВШЭ могут быть связаны с тем, что обследование не охватывает общежития и институциональные домохозяйства, где проживают преимущественно люди, не состоящие в браке.
} 
доли никогда не состоявших в браке. Наблюдаемые в РМЭЗ ВШЭ тренды совпадают с выводами российских демографов об удлинении периода взросления и увеличении разводимости в 1990-начале 2000-х годов (Захаров 2013; Митрофанова 2019).

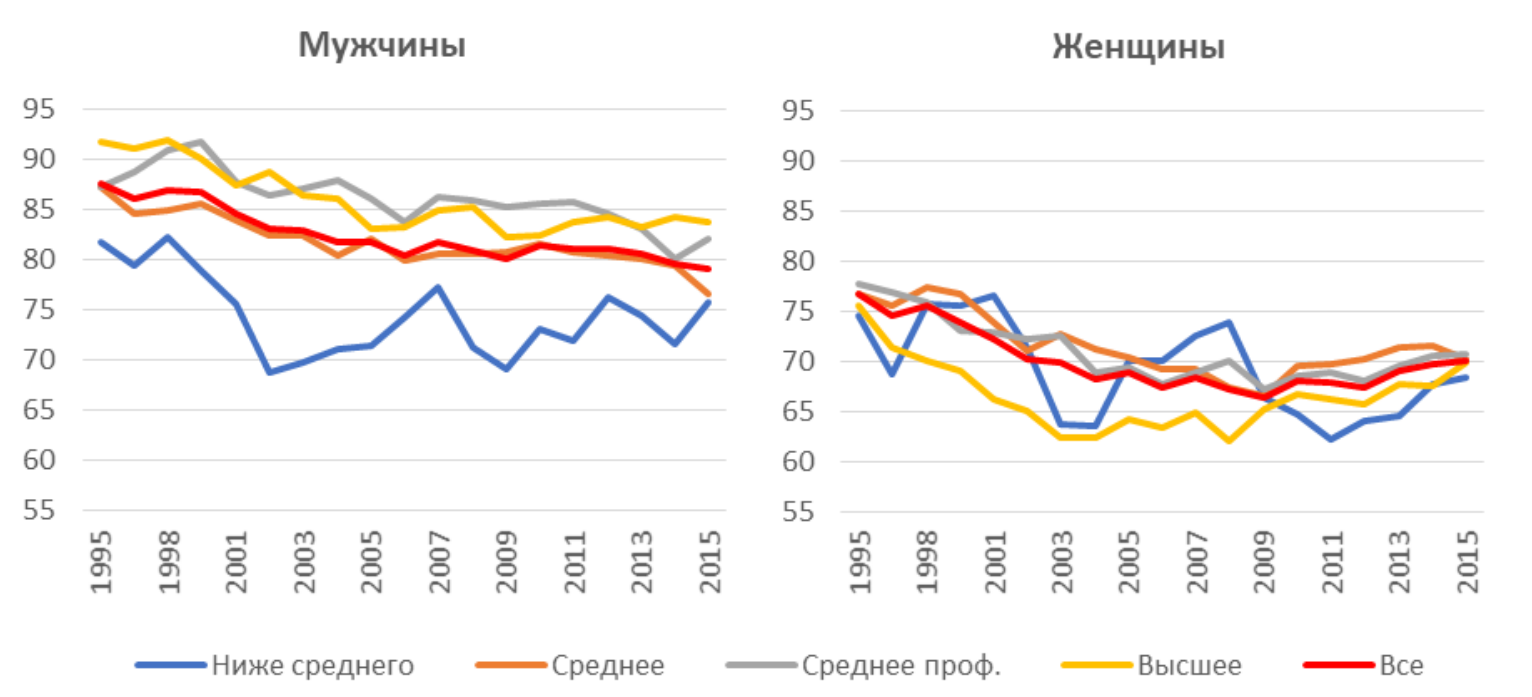

Рисунок 2. Доля мужчин и женщин в возрасте 30-50 лет, состоящих в браке

Источник: Расчеты автора по данным РМЭЗ ВШЭ.

Сокращение доли лиц, состоящих в браке, охватило все образовательные группы. У женщин это снижение происходило равномерно и составило 6-7 п.п. на всех уровнях образования. Вплоть до 2009 г. женщины с высшим образованием реже состояли в браке чем женщины с более низким уровнем образования, однако к 2015 г. это отставание исчезло. У мужчин наиболее глубокий «провал» (на 10-20 п.п. ниже, чем в других образовательных группах) фиксируется в категории с самым низким образованием. Именно в этой образовательной группе доля мужчин, состоящих в браке, была заметно ниже на протяжении всего рассматриваемого периода. Относительно низкие шансы малообразованных мужчин на брачном рынке могут быть обусловлены их низкой привлекательностью с точки зрения зарплатного потенциала.

В результате произошедших изменений к середине 2010-х годов доля женщин, состоящих в браке, слабо варьировала по уровням образования и составляла около $70 \%$. Среди мужчин образование сильнее влияет на вероятность состоять в браке. На протяжении всего рассматриваемого периода доля мужчин, состоящих в браке, была заметно выше среди выпускников вузов и ссузов.

Наряду с сокращением доли населения, состоящего в браке, в 1995-2015 гг. происходило изменение образовательной структуры семейных пар. На рисунке 3 представлено соотношение уровней образования мужей и жен для обоих полов. Однако в гендерном разрезе образовательные структуры пар фактически совпадают, поскольку разница в возрасте мужей и жен, как правило, незначительна и в большинстве браков оба супруга участвуют в нашей выборке. В рассматриваемый период самой распространенной моделью брака для 30-50-летних является союз между мужчинами и женщинами с одинаковым образованием. В 2015 г. гомогамные браки составляли примерно 45\% от 
общего числа супружеских пар, что ниже, чем в 1995 г.: на 4 п.п. среди мужчин и на 2 п.п. среди женщин. Уменьшение гомогамии происходило за счет роста доли пар, в которых жена более образована, чем муж (на 5 п.п. среди мужчин и на 3 п.п. среди женщин). Доля пар, в которых муж более образован, чем супруга, также снизилась, но менее значительно ${ }^{4}$.

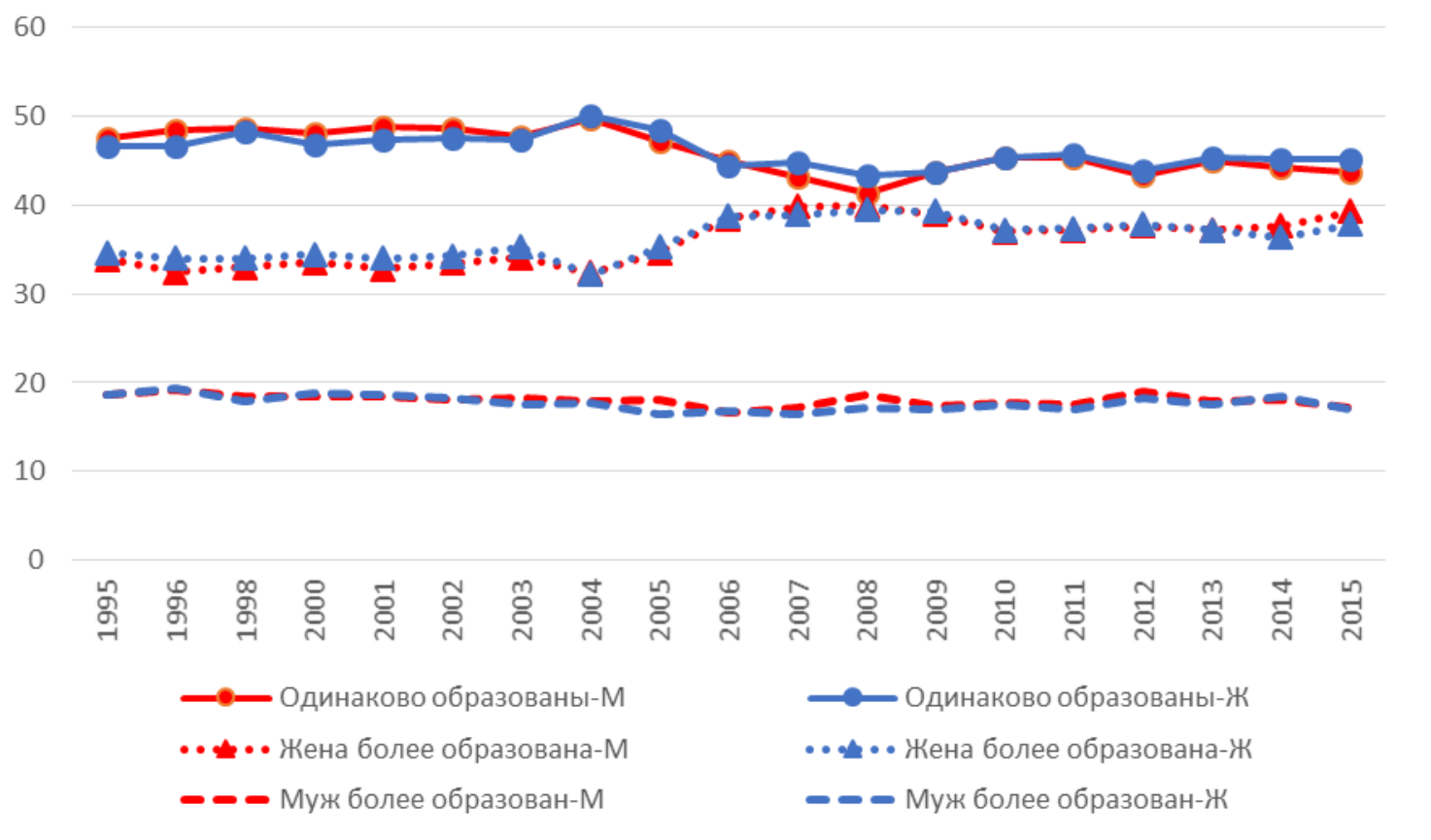

\section{Рисунок 3. Состав семей с точки зрения образования супругов}

Источник: Расчеты автора по данным РМЭЗ ВШЭ.

В таблице 1 показана динамика брачной структуры в зависимости от уровня образования. Сокращение представленности гомогамных браков происходило крайне неравномерно по уровням образования и по разным траекториям для мужчин и женщин. У женщин снижение гомогамии наблюдалось во всех группах за исключением среднего профессионального образования, тогда как у мужчин это сокращение фиксировалось прежде всего среди имеющих полное среднее образование.

Среди мужской половины четко прослеживается тенденция увеличения доли браков с более образованными женщинами. Это видно в заметном увеличении доли гипогамных браков для групп со средним и средним профессиональным образованием. Среди мужчин с высшим образованием увеличилась доля тех, кто состоит в гомогамном браке, и снизилась доля тех, кто состоит в гипергамном союзе. Таким образом, мы видим признаки того, что со стороны мужчин все выше готовность отступить от гендерных стереотипов и вступить в

\footnotetext{
${ }^{4}$ Для сравнения: По данным Всесоюзной переписи 1979 г. среди замужних женщин 30-49 лет состояли в гомогамных браках около 48\%, в гипогамных - 28\%, в гипергамных - 24-25\%. При этом резкое увеличение доли гипогамных союзов (с 20 до 29\%) за счет гомогамных браков, доля которых снизилась с 55 до 47\%, произошло в когорте родившихся в 1935-1939 гг. и закрепилось в последующих когортах (Волков 1986). Ключевым фактором резкого изменения структуры явилась, по-видимому, массовизация среднего образования.
} 
брак с женщиной, имеющей такой же или более высокий уровень образования. Единственной группой мужчин, в которой наблюдался рост доли гипергамных союзов, являются обладатели среднего образования.

Таблица 1. Распределение женщин и мужчин в возрасте 30-50 лет по уровню образования супруга(и), \% от численности соответствующей образовательной группы

\begin{tabular}{|c|c|c|c|c|c|c|c|c|c|}
\hline \multirow[b]{2}{*}{ Образование } & \multicolumn{3}{|c|}{1995} & \multicolumn{3}{|c|}{2015} & \multicolumn{3}{|c|}{ Изменение за 1995-2015 гг., п.п. } \\
\hline & 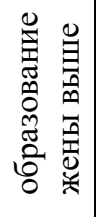 & 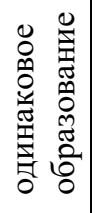 & 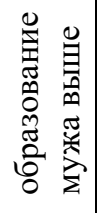 & 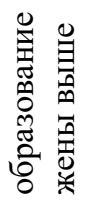 & 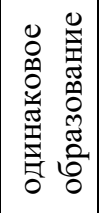 & 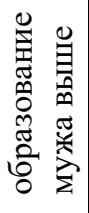 & 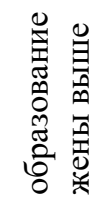 & 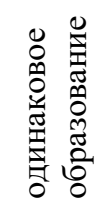 & 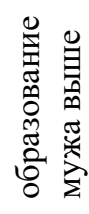 \\
\hline \multicolumn{10}{|c|}{ А. Женщины } \\
\hline Ниже среднего & - & 42,0 & 58,0 & - & 38,2 & 61,8 & - & $-3,8$ & 3,8 \\
\hline Среднее & 14,3 & 65,1 & 20,6 & 17,2 & 57,3 & 25,5 & 2,9 & $-7,8$ & 4,9 \\
\hline Среднее проф. & 61,4 & 19,0 & 19,6 & 60,2 & 24,6 & 15,2 & $-1,2$ & 5,6 & $-4,4$ \\
\hline Высшее & 48,0 & 52,0 & 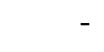 & 50,5 & 49,5 & - & 2,5 & $-2,5$ & - \\
\hline \multicolumn{10}{|c|}{ Б. Мужчины } \\
\hline Ниже среднего & 79,7 & 20,3 & - & 77,5 & 22,5 & - & $-2,2$ & 2,2 & - \\
\hline Среднее & 40,7 & 52,9 & 6,4 & 51,7 & 38,5 & 9,8 & 11,0 & $-14,4$ & 3,4 \\
\hline Среднее проф. & 22,2 & 43,2 & 34,6 & 34,7 & 33,8 & 31,5 & 12,5 & $-9,4$ & $-3,1$ \\
\hline Высшее & - & 50,7 & 49,3 & - & 70,6 & 29,4 & - & 19,9 & $-19,9$ \\
\hline
\end{tabular}

Источник: Расчеты автора по данным РМЭЗ ВШЭ.

К 2015 г. для мужчин гомогамный брак остался доминирующим выбором только в группе с высшим образованием. Среди мужчин со средним образованием гомогамия как доминирующий паттерн брака сменилась гипогамией. Наконец, мужчины со средним профессиональным образованием с примерно равной вероятностью состояли в браке с женщиной, имеющей такой же, более низкий и более высокий уровень образования.

На стороне женщин мы не видим столь же заметного увеличения доли состоящих в гипогамных союзах. Несовпадение трендов не должно удивлять, поскольку на изменения в ассортативности браков накладываются гендерные различия в образовательных трендах и уровнях брачности. Так, доля женщин, состоящих в браке с менее образованным мужчиной, увеличилась среди обладательниц общего среднего и высшего образования, тогда как среди женщин со средним профессиональным образованием доля гипогамии почти не изменилась. Женщины с высшим образованием стали чаще вступать в союз с менее образованным мужчиной скорее всего по причине опережающего роста охвата женщин высшим образованием. Одновременно среди женщин со средним образованием и ниже отмечалось увеличение частоты гипергамных браков. Таким образом, среди женщин не наблюдается однозначного смещения брачных паттернов в пользу гипогамных союзов. Наблюдаемые расхождения в трендах для мужчин и женщин соответствуют результатам исследований по западным странам, в которых часто подчеркивается более быстрая адаптация брачных предпочтений мужчин по сравнению с женщинами (van Bavel, Schwartz, Esteve 2018). 


\section{ХАРАКТЕРИСТИКИ РЕГИОНАЛЬНОГО БРАЧНОГО РЫНКА}

Наша эконометрическая модель строится на основе теории поиска партнера (Lichter, Anderson, Hayward 1995; Oppenheimer 1988). В соответствии с этой теорией на поиск брачного партнера оказывают влияние две группы факторов: 1) факторы микроуровня, т. е. индивидуальные характеристики человека, которые влияют на готовность вступить в брак, предпочтения в отношении желаемого партнера, его/ее привлекательность для потенциальных супругов; 2) факторы макроуровня, относящиеся к социальнодемографическим характеристикам локальных брачных рынков.

Роль образования традиционно рассматривалась с позиций микроуровня как индивидуальная характеристика, которая улучшает шансы мужчин (а с недавнего времени, но не повсеместно, и женщин) на вступление в брак. Предшествующие исследования показали, что образование оказывает различное влияние на брачный статус на разных стадиях жизненного цикла. Студенты вузов, как правило, откладывают вступление в брак до завершения образования и начала трудовой карьеры, и в начале взрослой жизни доля состоящих в браке среди них ниже, чем среди менее образованных сверстников. Однако к 30 годам ситуация меняется на противоположную и доля состоящих в браке среди имеющих высшее образование превышает соответствующие показатели в других образовательных группах (Cherlin 2010).

В более широком смысле существенное значение имеют характеристики локального брачного рынка. Достаточно много работ (Becker 1973, 1974, 1991; Abramitzky, Delavande, Vasconcelos 2011; Banerjee et al. 2013), в том числе по России (Ильина 1977; Brainerd 2017), посвящено изучению влияния соотношения полов (sex ratio) на вероятность состоять в брачных отношениях и на возраст вступления в брак, а также на избирательность браков по уровню образования и социальному статусу. Соотношение полов, т. е. отношение численности мужчин к численности женщин, характеризует общую демографическую ситуацию и отражает «физическую доступность» потенциальных партнеров. Уменьшение соотношения полов укрепляет позиции мужчин, увеличивая их долю состоящих в браке и позволяя мужчинам выбирать жен из числа женщин с более высоким уровнем образования и социальным статусом. Есть работы, оспаривающие первый из этих выводов и показывающие, что «дефицит» мужчин может вести к сокращению доли состоящих в браке среди мужской части населения, поскольку у мужчин появляется больше возможностей иметь сексуальные связи без брачных обязательств (Angrist 2002; Warner et al. 2011). На женщин «дефицит» мужчин во всех исследованиях оказывает негативное влияние, снижая их переговорную силу, сокращая вероятность состоять в браке и увеличивая долю союзов с партнерами, обладающими более низким уровнем образования и социальным статусом.

В сравнительно небольшом числе работ изучалось влияние образовательных переменных, измеренных на региональном уровне. В одной из первых работ по США на эту тему Льюис, Оппенгеймер (Lewis, Oppenheimer 2000) показали, что в регионах с высокой долей образованного населения как мужчины, так и женщины имеют более высокие шансы вступить в брак с партнером, имеющим такой же или более высокий уровень образования. В регионах с высокой долей малообразованного населения женщины 
чаще вступают в брак с менее образованным партнером, причем риски гипогамии растут по мере увеличения возраста вступления в брак. Большая часть наблюдаемого в последние десятилетия прироста образовательной гомогамии и гипогамии связывается со сдвигами в образовательной структуре населения (Liu, Lu 2006; Gihleb, Lang 2020). Оживление интереса к теме влияния образовательных макропеременных началось после того, как в развитых странах было зафиксировано изменение знака гендерного дисбаланса в уровне образования в пользу женщин. В частности, на агрегированных данных по большому числу стран мира было показано, что повышение относительного уровня образования женщин ведет к снижению распространенности гипергамии за счет роста гомо- и гипогамных браков (Esteve, García-Román, Permanyer 2012). Де Хау и соавторы (De Hauw, Grow, van Bavel 2017) на основе микроданных по 28 европейским странам пришли к выводу, что более быстрое сокращение доли женщин с низким уровнем образования привело к снижению шансов низкообразованных мужчин вступить в брак. Женщины с высоким уровнем образования в ситуации «дефицита» высокообразованных мужчин предпочитают создавать семью с менее образованным партнером, нежели оставаться одинокими. Мужчины медленно отказываются от традиционной роли основного кормильца, среди них не было отмечено значимого увеличения вероятности брака с более образованными женщинами.

Для исследования влияния образования на брачный статус и избирательность браков мы добавили к данным РМЭЗ ВШЭ образовательные переменные регионального уровня, сформированные по данным ОРС: 1) долю лиц с высшим образованием в численности населения региона в возрасте 30-50 лет; 2) показатели экспансии высшего образования в возрастной группе 30-50 лет, которые определяли как разницу между долей лиц с высшим образованием в численности населения региона в текущем году и соответствующей долей в 1992 г. 5 ; 3) меры гендерного дисбаланса в образовательной структуре населения региона с учетом интервалов «подходящих» возрастов. Дополнительно в качестве контрольной переменной в регрессию было включено соотношение численности мужчин и женщин «подходящего» возраста (в логарифмах). Последний показатель был рассчитан на основании сделанных Росстатом оценок численности постоянного населения. Порядок создания этих переменных описан ниже.

Для формирования региональных переменных необходимо было определить границы «подходящего возраста». На основе данных РМЭЗ ВШЭ по лицам, состоящим в браке, были рассчитаны разности в возрасте между мужьями и женами (данные объединяли за все годы и по всем регионам). Далее для каждого года возраста отдельно для мужчин и женщин определяли медианное значение, 10-й и 90-й процентили и (на их основе) границы интервалов, в которые входят $80 \%$ различий в возрасте мужей и жен. Для рассматриваемых возрастов медианное значение разности в возрасте составило 2 года в пользу мужчин. Интервалы, включающие 80\% значений разности, как для мужчин, так и для женщин составили 10 лет. Так, для 80\% женщин 30-36 лет эта разница укладывается в интервал между «моложе мужа на 8 лет» и «старше мужа на 2 года». В более старших возрастах у женщин интервал смещается в сторону промежутка между «моложе мужа на

\footnotetext{
${ }^{5}$ Выбор 1992 г. в качестве базы продиктован прежде всего тем, что с этого года начинается ряд данных ОРС.
} 
7 лет» и «старше мужа на 3 года». Для мужчин в возрасте 30-50 лет 80\%-е интервалы составили промежуток между «моложе жены на 3 года» и «старше жены на 7 лет».

Описание процедуры создания региональных переменных мы начнем с переменной соотношения полов, поскольку на ее примере можно нагляднее всего показать, как использовалась концепция «подходящего возраста». Вычисления делали на основе расчетных данных Росстата о численности постоянного населения по следующей формуле (для упрощения записи в формуле опущены индексы года и региона):

$$
S R_{i}^{S}=\frac{C_{[a g e s]_{i}}^{m}}{C_{[a g e s]_{i}}^{f}},
$$

где: $s$ - пол, $i$ - возраст (в годах), ages - интервал «подходящих возрастов». В числителе стоит численность мужчин «подходящего» возраста, т. е. входящих в соответствующий $80 \%$-й интервал, для лиц, имеющий пол $s$ и возраст $i$. В знаменателе - численность женщин «подходящего» возраста для группы мужчин, определенной в числителе ${ }^{6}$. Теоретически величина $S R_{i}^{S}$ может изменяться от нуля до бесконечности, но в реальности значения $S R_{i}^{S}$ лежат в гораздо более узком интервале. Чем больше величина $S R_{i}^{S}$, тем больше мужчин «подходящего» возраста приходится на одну женщину «подходящего» возраста. Соответственно, сокращение $S R_{i}^{S}$ снижает шансы женщин найти супруга и наоборот увеличивает шансы мужчин найти супругу. Соотношение, равное единице, характеризует ситуацию, когда численности брачных когорт одинаковы. Показатели $S R_{i}^{S}$ варьируются по годам, регионам, полу и возрасту.

Рассмотрим пример расчета показателя $S R_{i}^{S}$ для женщин 40 лет, проживающих в г. Москве в 2000 г. По данным РМЭЗ ВШЭ, для замужних женщин 40 лет медианная разница в возрасте с мужьями составляет 2 года, и $80 \%$ из них состоят в браке с мужчинами, возраст которых лежит в промежутке между «моложе жены на 3 года» и «старше жены на 7 лет». «Подходящими» по возрасту брачными партнерами для 40-летней москвички будем считать москвичей в возрасте 37-47 лет. Их численность в 2000 г. из данных Росстата является числителем в формуле (1). Для расчета знаменателя мы берем медианный возраст мужей 40-летних женщин, т. е. 42 года, и смотрим, какой 80\%-й интервал возрастов обычен для брака мужчин этого возраста. Для 42-летних мужчин - это женщины, чей возраст находится в промежутке «моложе на 7 лет» и «старше на 3 года», т. е. женщины в возрасте 35-45 лет. Соответственно, в знаменателе формулы (1) будет численность женщин в возрасте 35-45 лет, проживавших в г. Москве в 2000 г., которая берется из данных Росстата.

Аналогичным образом рассчитывали показатели $S R_{i}^{S}$ для женщин каждого возраста (по годам), региона из выборки РМЭЗ ВШЭ и года обследования. Для мужчин расчеты проводили по сходной процедуре, только сначала определяли величину знаменателя, а затем - величину числителя. На рисунке 4 показана динамика соотношения численности женщин и мужчин «подходящего» возраста по регионам, входящим в выборку

\footnotetext{
${ }^{6}$ В расчетах учитывали численность мужчин и женщин без учета состояния в браке. 
РМЭЗ ВШЭ7 . Графики в целом схожи для мужчин и женщин, но со сдвигом вверх для мужчин в начале периода. Показатели $S R_{i}^{S}$ принимают значения меньше 1, что соответствует ситуации превышения численности женщин в «подходящих» возрастах над численностью «подходящих» мужчин. В нашем случае постоянный перевес численности женщин определяется в том числе ограничением выборки респондентами в возрасте 30-50 лет. Данный результат соответствует расчетам демографов: в России перелом половых пропорций фиксируется именно в возрасте 30 лет, затем «дефицит» мужчин начинает только нарастать.

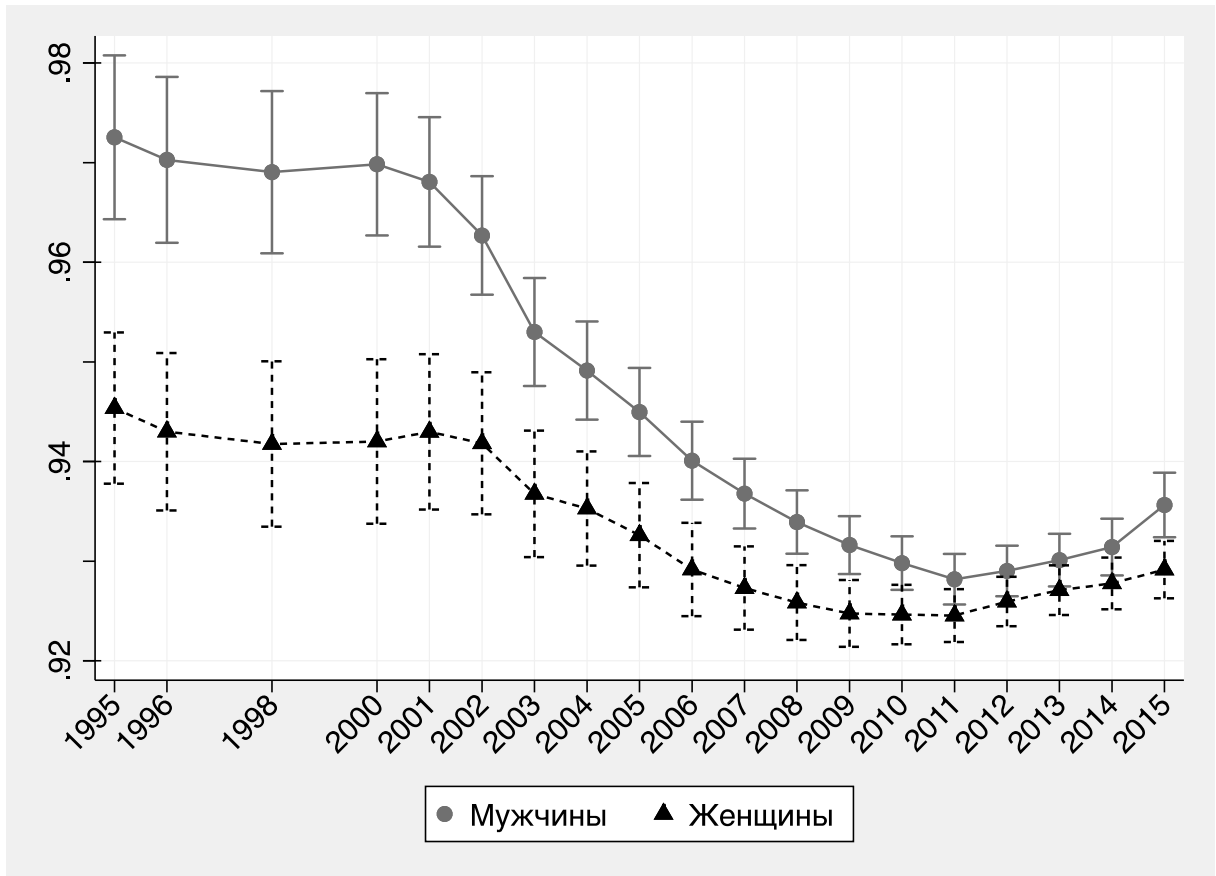

\section{Рисунок 4. Соотношение численности мужчин и женщин «подходящего» возраста}

Источник: Расчеты автора по данным Росстата для регионов, входящих в выборку РМЭЗ ВШЭ.

Долю лиц с высшим образованием в общей численности населения региона рассчитывали на основе данных ОРС по населению в возрасте 30-50 лет как отношение численности лиц с высшим образованием (как мужчин, так и женщин) к общей численности населения. На рисунке 5 показана тенденция роста доли лиц с высшим образованием в регионах из РМЭЗ ВШЭ.

Показатель гендерного дисбаланса в образовательной структуре населения региона рассчитывали по формуле, предложенной в работе Эстев и соавторов (Esteve, GarcíaRomán, Permanyer 2012) (для упрощения записи в формуле опущены индексы года, региона и интервала «подходящего» возраста):

$$
F=\frac{p_{f}^{4}\left(p_{m}^{1}+p_{m}^{2}+p_{m}^{3}\right)+p_{f}^{3}\left(p_{m}^{1}+p_{m}^{2}\right)+p_{f}^{2} p_{m}^{1}}{1-\left(p_{f}^{1} p_{m}^{1}+p_{f}^{2} p_{m}^{2}+p_{f}^{3} p_{m}^{3}+p_{f}^{4} p_{m}^{4}\right)}
$$

\footnotetext{
${ }^{7}$ Для каждого года обследования значения показателя взвешены по доле людей в соответствующих возрастных группах с учетом пола и региона проживания, а затем усреднены по всем регионам.
} 
где: $p_{f}^{e d u c}$ и $p_{m}^{e d u c}$ обозначают долю женского и мужского населения с различным уровнем образования: 4 - высшее; 3 - среднее профессиональное и неполное высшее; 2 - среднее; 1 - ниже среднего.

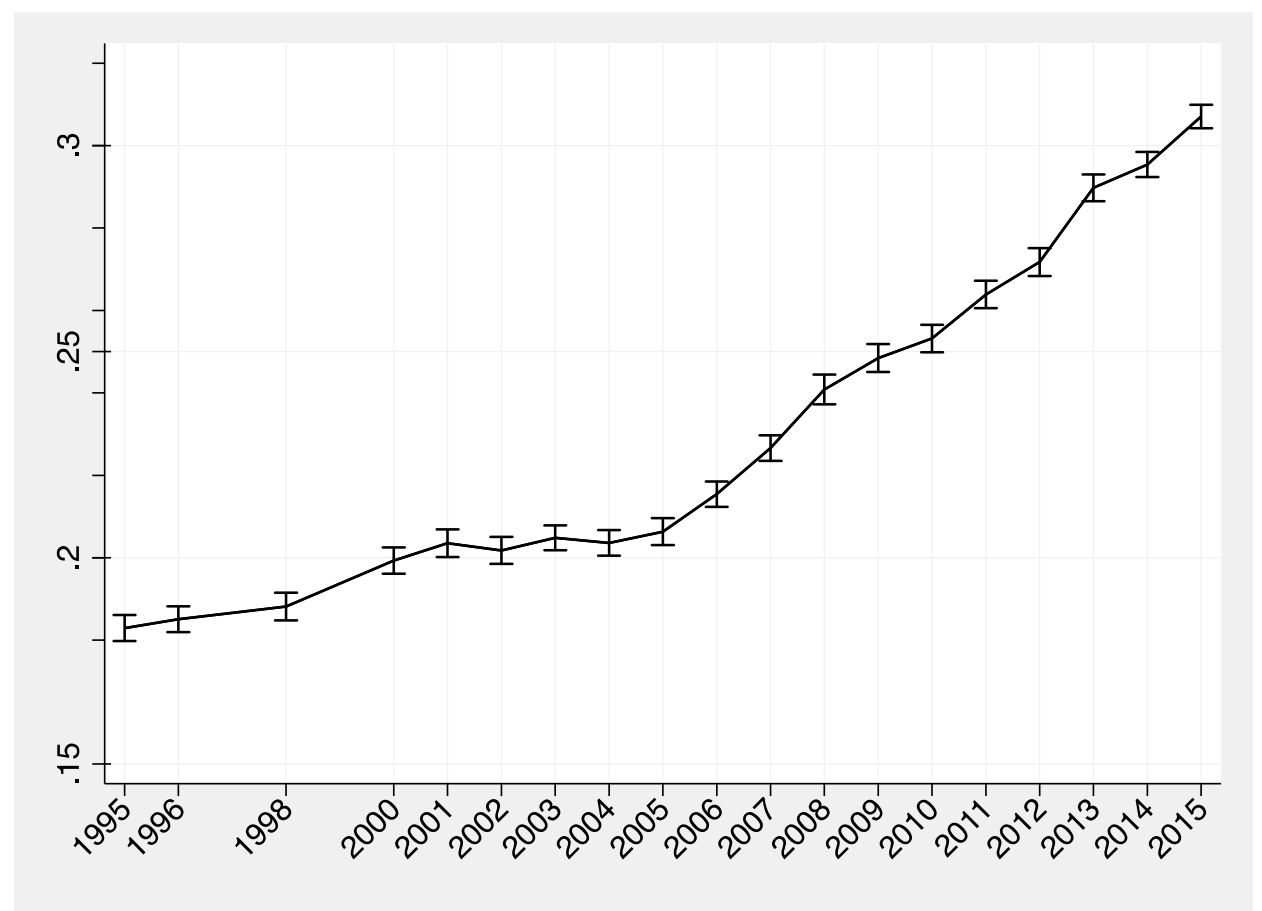

\section{Рисунок 5. Доля лиц с высшим образованием в общей численности населения региона в возрасте 30-50 лет}

Источник: Расчеты автора по данным ОРС для регионов, входящих в выборку РМЭЗ ВШЭ.

Математически величина $F$ показывает, с какой вероятностью случайно выбранная женщина, проживающая в данном регионе в данном году, будет иметь более высокий уровень образования, чем случайно выбранный мужчина «подходящего» возраста из того же региона и того же года обследования. Показатели $F$ принимают значения от 0 до 1 . Если $F=0$, то в регионе нет ни одной женщины, уровень образования которой выше или равен уровню образования любого из проживающих в регионе мужчин «подходящего» возраста. Ситуация $F=1$ означает, что все женщины имеют более высокий уровень образования, чем любой из мужчин «подходящего» возраста. Если образовательные структуры мужчин и женщин «подходящего» возраста одинаковы, то $F=0,5$. Величина $F$ варьируется по годам, регионам, полу и возрасту.

На рисунке 6 показано изменение гендерного дисбаланса в структуре образования населения регионов, входящих в выборку РМЭЗ ВШЭ. Для каждого года обследования значения показателя взвешены по доле людей в соответствующих возрастных группах, сгруппированных по признакам пола и региона проживания, а затем усреднены по всем регионам. На рисунке 6 видно, что в среднем женщины более образованны, чем мужчины $(\bar{F}>0,5)$, и среднее значение показателя по регионам возрастало с начала 2000-х годов, указывая на усиление гендерного дисбаланса в сфере образования в пользу женщин. 


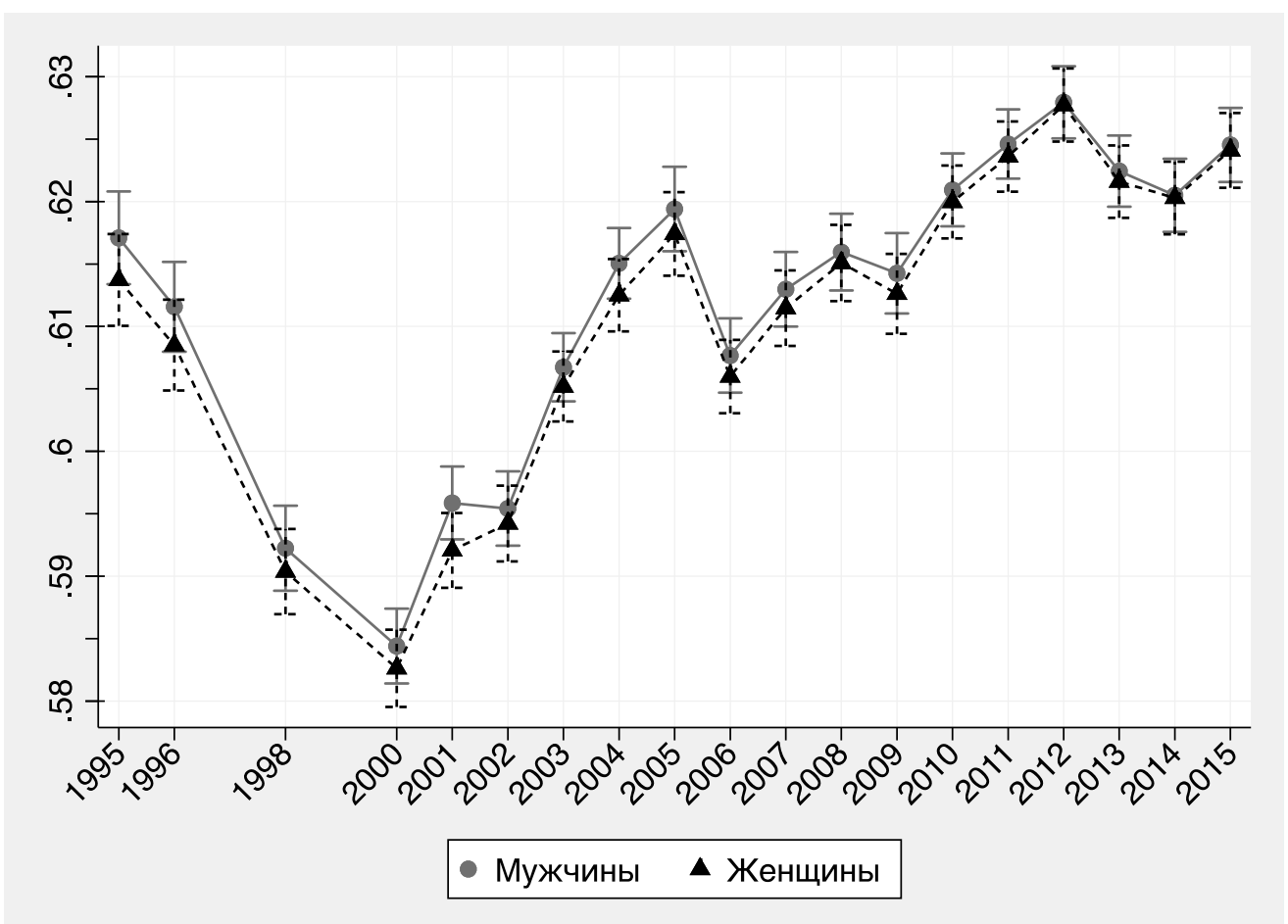

\section{Рисунок 6. Гендерный дисбаланс в образовательной структуре населения в возрасте 30-50 лет}

Источник: Расчеты автора по данным ОРС для регионов, входящих в выбборку РМЭЗ ВШЭ.

\section{ЭМПИРИЧЕСКИЕ РЕЗУЛЬТАТЫ}

По объединенным данным мы оценивали мультиномиальную логистическую регрессию отдельно для женщин и мужчин. Зависимой переменной в уравнении является категориальная переменная, сформированная на основе информации о семейном положении индивида и уровне образования супруга(-и). Она принимает следующие значения: 1) не состоит в браке; 2) состоит в браке и образование супруга(-и) ниже; 3) состоит в браке, и супруг(-а) имеет такой же уровень образования; 4) состоит в браке, и образование супруга(-и) выше. В качестве независимых переменных в уравнение были включены уровень образования, возраст, квадрат возраста, признак этнической принадлежности (1 - русский(-ая), 0 - все остальные), тип населенного пункта (1 - город, $0-$ село) и набор переменных для каждого года обследования. Чтобы учесть пространственную неоднородность брачного поведения, мы включили фиктивные переменные для федеральных округов. Дополнительно в модели были учтены характеристики локальных брачных рынков. Результаты расчетов представлены в виде средних предельных эффектов отдельно для женщин и мужчин в таблицах 2 и 3 соответственно.

Результаты, представленные в таблицах 2 и 3, показывают, что получение высшего образования не снижает вероятность состоять в браке. Наоборот, у мужчин по мере роста уровня образования увеличивается вероятность быть женатым, пусть и с сокращением величины эффекта для высшего образования в сопоставлении с эффектом для среднего 
профессионального образования (однако эти различия не значимы). Так, при прочих равных по сравнению с обладателями среднего образования у выпускников вузов вероятность состоять в браке выше на 3,7 п.П., тогда как у тех, чье образование ниже среднего - ниже на 12,5 п.п. Для женщин отрицательное воздействие на вероятность быть замужем оказывает только низкий уровень образования. При этом величина эффекта $(15,2$ п.п.) превышает соответствующее значение для мужчин. Таким образом, независимо от пола лица с самым низким уровнем образования пользуются меньшей популярностью на брачном рынке. Среди женщин получение среднего профессионального образования повышает вероятность состоять в браке, а эффект высшего образования оказывается статистически незначимым. Эти результаты могут означать, что российское общество уже несколько продвинулось по пути демографической модернизации в части брачного поведения. Как говорилось во введении, в странах с традиционалистским укладом женщины с высшим образованием имеют более низкие шансы на вступление в брак.

\section{Таблица 2. Результаты оценивания модели брачного поведения женщин, средние предельные эффекты}

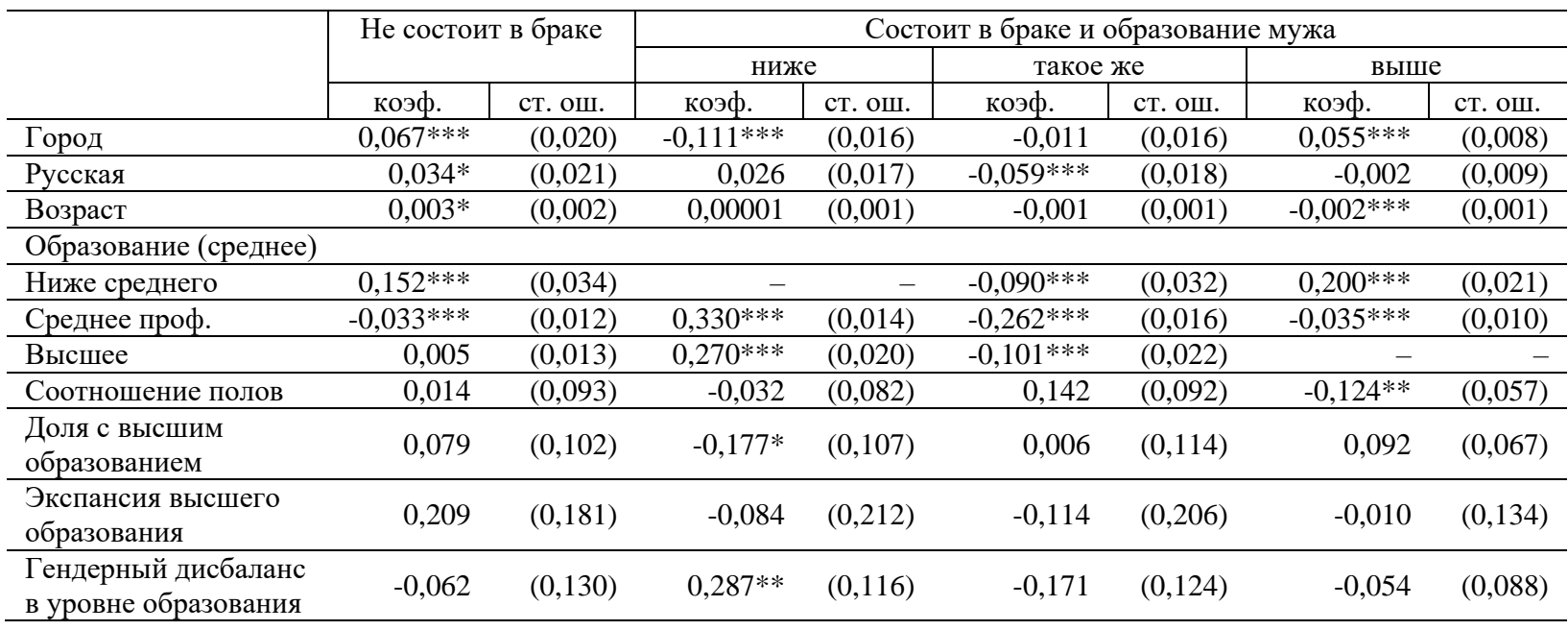

Источник: Расчеты автора по объединенным данным РМЭЗ ВШЭ, ОРС и Росстата.

Примечание: $N=33408$ В скобках приведены базовые категории. Робастные стандартные ошибки кластеризованы по регионам; ***, **, *-значимость на уровне 1, 5, и 10\% соответственно. В спецификацию наряду с перечисленными переменными включен набор фиктивных переменных для каждого года обследования и региона проживания на уровне федеральных округов.

В отношении выбора партнера гендерные различия проявляются более отчетливо. Среди мужчин вероятность состоять в гомогамном браке увеличивается по мере роста уровня образования. Мужчины с вузовским дипломом также имеют максимальные шансы на брак, в котором жена имеет более низкий уровень образования. Вероятность состоять в гипергамном союзе лишь немногим ниже для мужчин со средним профессиональным образованием. При этом для обеих групп эти шансы существенно выше, чем для выпускников школ. Гипогамные браки чаще всего встречаются среди обладателей низкого уровня образования, и по мере роста образовательного статуса вероятность состоять в подобном союзе снижается. Таким образом, брачное поведение мужчин, особенно обладателей среднего профессионального образования, тяготеет к довольно традиционной модели брака. В то же время среди обладателей очень низкого уровня образования и 
выпускников вузов эгалитарные паттерны избирательности браков проявляются сильнее, чем в других группах.

Таблица 3. Результаты оценивания модели брачного поведения мужчин, средние предельные эффекты

\begin{tabular}{|c|c|c|c|c|c|c|c|c|}
\hline & \multirow{2}{*}{\multicolumn{2}{|c|}{ Не состоит в браке }} & \multicolumn{6}{|c|}{ Состоит в браке и образование жены } \\
\hline & & & \multicolumn{2}{|c|}{ ниже } & \multicolumn{2}{|c|}{ такое же } & \multicolumn{2}{|c|}{ выше } \\
\hline & коэф. & ст. ош. & коэф. & ст. ош. & коэф. & ст. ош. & коэф. & ст. ош. \\
\hline Город & 0,013 & $(0,019)$ & $-0,027 * *$ & $(0,011)$ & $-0,010$ & $(0,018)$ & 0,024 & $(0,015)$ \\
\hline Русский & $0,031 *$ & $\begin{array}{l}(0,016) \\
\end{array}$ & $-0,016$ & $(0,014)$ & $-0,069 * * *$ & $(0,022)$ & $0,053 * * *$ & $(0,015)$ \\
\hline Возраст & $-0,008 * * *$ & $(0,001)$ & $0,002 * *$ & $(0,001)$ & $0,004 * * *$ & $(0,001)$ & $0,003 * *$ & $(0,001)$ \\
\hline \multicolumn{9}{|l|}{ Образование (среднее) } \\
\hline Ниже среднего & $0,125 * * *$ & $(0,026)$ & - & - & $-0,141 * * *$ & $(0,029)$ & $0,173 * * *$ & $(0,021)$ \\
\hline Среднее проф. & $-0,049 * * *$ & $(0,013)$ & $0,249 * * *$ & $(0,018)$ & $-0,092 * * *$ & $(0,026)$ & $-0,109 * * *$ & $(0,018)$ \\
\hline Высшее & $-0,037 * * *$ & $(0,013)$ & $0,287 * * *$ & $(0,023)$ & $0,125 * * *$ & $(0,027)$ & - & \\
\hline Соотношение полов & $-0,186^{*}$ & $(0,104)$ & $-0,011$ & $(0,065)$ & $0,302 * * *$ & $(0,100)$ & $-0,105$ & $(0,099)$ \\
\hline $\begin{array}{l}\text { Доля с высшим } \\
\text { образованием }\end{array}$ & $0,238 * * *$ & $(0,084)$ & $-0,160 * *$ & $(0,075)$ & $-0,177$ & $(0,153)$ & 0,099 & $(0,115)$ \\
\hline $\begin{array}{l}\text { Экспансия высшего } \\
\text { образования }\end{array}$ & $-0,118$ & $(0,202)$ & 0,079 & $(0,187)$ & 0,163 & $(0,327)$ & $-0,125$ & $(0,216)$ \\
\hline $\begin{array}{l}\text { Гендерный дисбаланс в } \\
\text { уровне образования }\end{array}$ & $-0,029$ & $(0,111)$ & $-0,099$ & $(0,095)$ & $-0,226^{*}$ & $(0,130)$ & $0,354 * * *$ & $(0,111)$ \\
\hline
\end{tabular}

Источник: Расчеты автора по объединенным данным РМЭЗ ВШЭ, ОРС и Росстата.

Примечание: $N=28657$. В скобках приведены базовые категории. Робастные стандартные ошибки кластеризованы по регионам; ***, **, *-значимость на уровне 1, 5, и 10\% соответственно. В спецификацию наряду с перечисленными переменными включен набор фиктивных переменных для каждого года обследования и региона проживания на уровне федеральных округов.

Среди женщин не наблюдается такой четкой корреляции между образованием и типом брака. Шансы состоять в гомогамном союзе максимальны для обладательниц среднего образования и значимо ниже для всех остальных групп. Сложнее всего найти супруга с аналогичным образовательным уровнем женщинам со средним профессиональным образованием: в этой группе чаще, чем в остальных, женщины состоят в браке с мужчиной с более низким образовательным статусом. Женщины с высшим образованием также чаще оказываются замужем за менее образованным мужчиной. Корреляция между имеющимся образованием и типом брака для женской половины населения прослеживается лишь в отношении гипергамного союза. Вероятность подобного брака у женщин снижается по мере роста их уровня образования. Таким образом, женщины, особенно со средним профессиональным и в меньшей степени с высшим образованием, ассоциируются с моделью брака, в которой муж имеет более низкий уровень образования.

Одновременно брачное поведение подчиняется действию социальнодемографических факторов брачного рынка, которые ограничивают совокупность возможных для конкретного индивида потенциальных партнеров. Полученные оценки говорят о том, что брачный статус мужчин и женщин слабо коррелирует с региональными характеристиками брачного рынка, демонстрируя при этом неодинаковую чувствительность к этим региональным факторам. Показатель соотношения численности мужчин и женщин не оказывает значимое воздействие на брачный статус, но ведет себя ожидаемым образом: увеличение относительной численности женского населения связано со снижением вероятности состоять в браке у женщин и с ее ростом у мужчин. Охват населения региона высшим образованием как экзогенный фактор сказывается на 
вероятности состоять в браке только у мужчин. Так, в регионах с высокой долей населения с высшим образованием ниже доля мужчин, состоящих в браке. Темпы экспансии высшего образования не оказывают воздействия на вероятность состоять в браке у обоих полов. Брачное поведение и мужчин, и женщин одинаковое как в регионах с быстрым развитием массового высшего образования, так и в территориальных единицах с более низким темпом его распространения. Гендерный дисбаланс в образовательной структуре населения региона также не оказывается важным фактором, влияющим на брачно-партнерский статус. Брачное поведение мужчин и женщин, проживающих в регионах с гендерной асимметрией в уровне образования в пользу женщин, оказывается эквивалентным поведению тех, кто проживает в регионах с более гендерно нейтральным образовательным апгрейдингом.

Поскольку поведение в семейной сфере не является произвольным, оно детерминировано в том числе экономическими и социокультурными условиями, существующими в обществе, то по-видимому, показатель охвата высшим образованием характеризует уровень экономического развития региона и степень модернизированности закрепленных в нем правил и социальных норм. Рост благосостояния в целом снижает выгоды от вступления в брак, а бо́льшая степень социальной свободы создает предпосылки для индивидуализации брачных установок. В условиях новых возможностей, создаваемых экономическим, технологическим и социокультурным развитием, само по себе высшее образование способствует развитию современных ценностных ориентаций и мотиваций брачного поведения прежде всего у мужчин.

Социально-демографические структуры региональных брачных рынков оказываются более значимыми факторами для избирательности браков по уровню образования. С диспропорцией в соотношении полов коррелирует брачный отбор со стороны обоих полов. Среди мужчин, проживающих в регионах с более равной представленностью мужского и женского населения, значимо выше вероятность состоять в гомогамном браке. В то время как для женщин из таких же регионов значимо ниже шансы состоять в гипергамном союзе ${ }^{8}$. От уровня охвата высшим образованием зависит только поведение мужчин в части выбора партнера. Для мужской половины, проживающей в регионах с высокой долей населения с высшим образованием, независимо от их собственного уровня образования наблюдается значимое снижение вероятности состоять в браке с женщиной, обладающей более низким образовательным статусом. Среди женщин влияние этого показателя на вероятность брака с партнером, имеющим более низкий уровень образования, также отрицательно, но его эффект незначим. Паттерны избирательности обоих полов не зависят от темпов экспансии высшего образования: брачное поведение и мужчин, и женщин в части выбора партнера одинаковое как в регионах с более быстрым развитием массовости высшего образования, так и в регионах, где этот охват рос медленнее. Гендерный дисбаланс оказывает воздействие на избирательность браков и женщин, и мужчин, но среди последних этот эффект выражен сильнее. Так, у мужчин, проживающих в регионах с более широким гендерным разрывом в

\footnotetext{
${ }^{8}$ Результат, свидетельствующий о росте вероятности гипергамного брака для женской части населения, проживающей в регионах с более сильным перекосом демографической структуры в пользу женщин, не соответствует теоретическим ожиданиям и нуждается в дополнительном изучении.
} 
образовании в пользу женщин, в целом выше вероятность состоять в браке с более «качественной» партнершей. Этот факт отражает рациональность брачного поведения: более высокое образование супруги увеличивает потенциальные экономические выгоды от брака. Среди женщин более сильный гендерный дисбаланс способствует увеличению вероятности брака с мужчиной с более низким образовательным статусом. Социальная приемлемость такого паттерна избирательности женщин требует дальнейшего изучения в контексте соотношения уровня образования и заработной платы между мужчинами и женщинами.

Обсудим другие факторы, влияющие на брачное поведение. Влияние проживания в городе имеет предсказуемое направление на брачный статус обоих полов, но оказывается значимым только для женщин. При прочих равных у жительниц городов вероятность быть замужем на 6,7 п.п. ниже, чем у жительниц сел. Городской образ жизни сокращает шансы обоих полов состоять в браке с партнером, обладающим более низким уровнем образования и одновременно увеличивает вероятность гипергамии у женщин. Брачный статус не дифференцируется по этнической принадлежности, что неверно для образовательной ассортативности. Для русского населения в меньшей мере, чем для других национальностей, вероятен брак с партнером, обладающим таким же уровнем образования. При этом русские мужчины и женщины чаще, чем представители других этносов, состоят в гипогамных союзах. Однако последний эффект оказывается значимым только для мужчин.

\section{ЗАКЛЮЧЕНИЕ}

Во многих странах катализатором трансформации брачного поведения служит повышение образовательного уровня населения, прежде всего за счет развития массового высшего образования. Наличие высшего образования ведет к повышению доходов и, как следствие, снижению экономических стимулов для вступления в брак, одновременно увеличивая издержки от союза с партнером, обладающим более низким уровнем образования. Более длительное пребывание в системе образования не только отодвигает создание семьи на более поздние возраста, но и увеличивает вероятность брака со столь же образованным партнером. Характеризуя ситуацию экспансии высшего образования, важно отметить, что образовательный апгрейдинг не был гендерно нейтральным: в России охват женщин высшим образованием уже несколько десятилетий опережает соответствующие показатели для мужчин. Данная работа ставит перед собой задачу рассмотреть связь между охватом высшим образованием, темпами расширения этого охвата, усилением гендерного дисбаланса в уровнях образования и брачным статусом российских граждан и образовательной ассортативностью их браков.

Результаты нашего исследования говорят о снижении доли состоящих в браке для обоих полов с охватом всех образовательных групп. Мы обнаруживаем, что образование сильнее влияет на брачный статус мужчин. Так, мужчины с низким уровнем образования реже более образованных состоят в семейных отношениях. Для женщин мы не находим негативного влияния высшего образования на вероятность состоять в браке. Последнее обстоятельство важно, поскольку оно подтверждает, что российское общество не является 
жестко традиционалистским, в нем происходит постепенное изменение гендерных установок и движение в сторону гендерного равенства.

В структуре браков также происходили важные изменения. На протяжении рассматриваемого периода отмечалось распространение доли пар, в которых жена более образована, чем муж. Этот рост происходил прежде всего за счет снижения образовательной гомогамии, которая по-прежнему остается доминирующим паттерном брака. Увеличение доли гипогамных союзов особенно четко прослеживается среди женщин со средним профессиональным образованием и в меньшей степени - среди женщин с высшим образованием. Подобный брачный отбор со стороны образованных женщин может являться альтернативой исходу остаться без пары или соотноситься с зарплатным потенциалом партнера. Ввиду наличия гендерного разрыва в оплате труда зарплата партнера с более низким уровнем образования может быть сопоставима с трудовым доходом образованной партнерши и даже превышать его. Существующий гендерный дисбаланс в образовательной структуре населения только усиливает такие эгалитарные паттерны образовательной избирательности женщин. При этом развитие массового высшего образования и темпы его распространения не оказывают воздействия ни на брачный статус женщин, ни на их паттерны ассортативности браков.

В отличие от образованных женщин образованные мужчины ориентированы на сценарий традиционалистской семьи, в которой жена менее образована, чем муж. Особенно явно такой паттерн избирательности отмечается у мужчин со средним профессиональным образованием. Мужчины с высшим образованием находятся в переходном положении на пути демографической модернизации в части брачного выбора, поскольку одновременно демонстрируют склонность как к традиционной, гипергамной, модели брака, так и к более эгалитарному, гомогамному, союзу. Возрастание гендерного дисбаланса в демографической и образовательной структурах населения в пользу женщин усиливает эгалитарные паттерны избирательности мужчин, сдвигая их предпочтения от гомогамии в сторону союза с более образованной женщиной. Брачный статус мужчин сильнее реагирует на образовательные тренды: у мужчин вероятность состоять в браке снижается по мере роста общей доли высокообразованного населения в регионе. При этом их избирательность браков не зависит от темпов роста охвата населения региона высшим образованием.

Наше исследование носит описательный характер, поэтому вопрос интерпретации полученных результатов в терминах причинно-следственной связи остался незатронутым и заслуживает дальнейшего изучения. В связи с чем крайне полезным был бы анализ дополнительных факторов, определяющих брачное поведение. Такими каналами влияния могут быть повышение отдачи от образования, положение в занятости и изменение гендерного разрыва в оплате труда.

\section{БЛАГОДАРНОСТИ}

Автор выражает благодарность за помощь в подготовке статьи научному руководителю А.Л. Лукьяновой. 


\section{ЛИТЕРАТУРА}

Бессуднов А.Р., Куракин Д.Ю., Малик В.М. (2017) Как возник и что скрывает миф о всеобщем высшем образовании. Вопросы образования, 3, 83-109.

Волков А.Г. (1986). Семья-объект демографии. Мысль.

Дарский Л.Е., Ильина И.П. (2000). Некоторые данные о социальной дифференциации брачности. В А.Г. Волков (Ред.), Брачность в России. Анализ таблии брачности (сс. 44-46). М.: Информатика.

Захаров С.В. (2013). Куда движется супружество в России? Демоскоn Weekly, 545-546. URL: http://demoscope.ru/weekly/2013/0545/tema06.php.

Зинченко Д.И., Лукьянова А.Л. (2018). Ассортативность браков по образованию и неравенство доходов. Экономический журнал Высшей школьл экономики, 22(2), 169196.

Зинченко Д.И., Лукьянова А.Л. (2021). Тенденции в избирательности браков по уровню образования: роль изменений в образовательной структуре населения. Мир России, 30(1), 111-133.

Итоги Всесоюзной переписи населения 1989 г. (1989). Распределение населения СССР, РСФСР, ее автономных республик, автономных областей и округов, краев и областей по уровню образования и возрасту. Демоскоn Weekly. Приложения. URL: http://www.demoscope.ru/weekly/ssp/rus_edu_89.php?reg=2

Ильина И.П. (1977). Влияние войн на брачность советских женщин. В А.Г. Вишневский (Ред.), Брачность, рождаемость, смертность в России и в СССР (сс. 50-61). М.: Статистика.

Росстат (2015). Микроперепись населения 2015 г. URL: https://gks.ru/free_doc/new_site/population/demo/micro-perepis/finish/micro-perepis.html

Митрофанова Е.С. (2019). Модели взросления разных поколений россиян. Демографическое обозрение, 6(4), 53-82.

Рощина Я.М., Рощин С.Ю. (2008). Брачный рынок в России: выбор партнера и факторы успеха. Математическое моделирование, 4, 21-37.

Abramitzky R., Delavande A., Vasconcelos L. (2011). Marrying up: the role of sex ratio in assortative matching. American Economic Journal: Applied Economics, 3(3), 124-57.

Angrist J. (2002). How do sex ratios affect marriage and labor markets? Evidence from America's second generation. The Quarterly Journal of Economics, 117(3), 997-1038.

Banerjee A., Duflo E., Ghatak M., Lafortune J. (2013). Marry for what? Caste and mate selection in modern India. American Economic Journal: Microeconomics, 5(2), 33-72.

Becker G.S. (1973). A theory of marriage: Part I. Journal of Political Economy, 81(4), 813-846.

Becker G.S. (1974). A theory of marriage: Part II. Journal of Political Economy, 82(2, Part 2), 11-26.

Becker, G. S. (1991). A treatise on the family: Enlarged edition. Harvard university press.

Bertrand M., Cortés P., Olivetti C., Pan J. (2016). Social norms, labor market opportunities, and the marriage gap for skilled women (No. w22015). National Bureau of Economic Research.

Blossfeld H.P., Timm A. (Eds.). (2003). Who marries whom?: educational systems as marriage markets in modern societies (Vol. 12). Springer Science \& Business Media. 
Brainerd E. (2017). The lasting effect of sex ratio imbalance on marriage and family: Evidence from World War II in Russia. Review of Economics and Statistics, 99(2), 229-242.

Cherlin A.J. (2010). Demographic trends in the United States: A review of research in the 2000s. Journal of Marriage and Family, 72(3), 403-419.

Chiappori P.A., Iyigun M., Weiss Y. (2009). Investment in schooling and the marriage market. American Economic Review, 99(5), 1689-1713.

De Hauw Y., Grow A., van Bavel J. (2017). The reversed gender gap in education and assortative mating in Europe. European Journal of Population, 33(4), 445-474.

Esteve A., García-Román J., Permanyer I. (2012). The gender-gap reversal in education and its effect on union formation: the end of hypergamy? Population and Development Review, 38(3), 535-546.

Esteve A., Schwartz C.R., van Bavel J., Permanyer I., Klesment M., Garcia J. (2016). The end of hypergamy: Global trends and implications. Population and Development Review, 42(4), 615.

Isen A., Stevenson B. (2010). Women's education and family behavior: Trends in marriage, divorce and fertility (No. w15725). National Bureau of Economic Research.

Gihleb R., Lang K. (2020). Educational homogamy and assortative mating have not increased. Emerald Publishing Limited.

Goldin C., Katz L.F., Kuziemko I. (2006). The homecoming of American college women: The reversal of the college gender gap. Journal of Economic Perspectives, 20(4), 133-156.

Kalmijn M. (2013). The educational gradient in marriage: A comparison of 25 European countries. Demography, 50(4), 1499-1520.

Lewis S.K., Oppenheimer V.K. (2000). Educational assortative mating across marriage markets: Nonhispanic whites in the United States. Demography, 37(1), 29-40.

Lichter D.T., Anderson R.N., Hayward, M.D. (1995). Marriage markets and marital choice. Journal of Family Issues, 16(4), 412-431.

Liu H., Lu J. (2006). Measuring the degree of assortative mating. Economics Letters, 92(3), 317322.

Nielsen H.S., Svarer M. (2009). Educational homogamy how much is opportunities? Journal of Human Resources, 44(4), 1066-1086.

Oppenheimer V.K. (1988). A theory of marriage timing. American Journal of Sociology, 94(3), 563-591.

Oppenheimer V.K. (1997). Women's employment and the gain to marriage: The specialization and trading model. Annual Review of Sociology, 23(1), 431-453.

Perelli-Harris B., Lyons-Amos M. (2016). Partnership patterns in the United States and across Europe: the role of education and country context. Social Forces, 95(1), 251-282.

Schwartz C.R., Han H. (2014). The reversal of the gender gap in education and trends in marital dissolution. American Sociological Review, 79(4), 605-629.

Schwartz C.R., Mare R.D. (2005). Trends in educational assortative marriage from 1940 to 2003. Demography, 42(4), 621-646.

Schofer E., Meyer J.W. (2005). The worldwide expansion of higher education in the twentieth century. American Sociological Review, 70(6), 898-920. 
Van Bavel J., Schwartz C.R., Esteve A. (2018). The reversal of the gender gap in education and its consequences for family life. Annual Review of Sociology, 44, 341-360.

Warner T.D., Manning W.D., Giordano P.C., Longmore M.A. (2011). Relationship formation and stability in emerging adulthood: Do sex ratios matter? Social Forces, 90(1), 269-295. 


\title{
THE EXPANSION OF HIGHER EDUCATION AND ITS IMPACT ON PATTERNS OF UNION FORMATION AND ASSORTATIVE MATING: EVIDENCE FROM RUSSIA
}

\section{DARIAZINCHENKO}

\begin{abstract}
The paper aims to investigate the consequences of the gender-biased expansion of higher education for the marriage patterns and educational assortative mating of men and women in Russia. The effect of education is introduced at two levels: as an individual trait and as a feature of the local marriage market. Using multinomial logit regressions, we assess how a person's own education attainment affects the likelihood of being married and the choice of a partner with a certain educational level. Changes in the educational composition of the local marriage market are an exogenous factor. Results show that men's level of education increases their chances of being married, while for women, a university degree does not affect the likelihood of their being married. The educational structure of the local marriage markets only slightly correlates with union formation and has a more pronounced effect on educational assortative mating. Women's advantage in education fosters the already expanding tendency towards hypogamy among women. Men, however, tend to react more rationally to the reinforced women's educational advantage, shifting their preferences from homogamy to a union with more educated women with potentially more appealing economic characteristics. The share of university graduates in the total population is statistically related to educational sorting only of men. Among men, the probability of marrying a less educated woman decreases as the share of university-educated people grows. However, the rates of expansion of higher education do not have significant implications for the educational sorting of both women and men.
\end{abstract}

Key words: higher education, marriage behavior, educational assortative mating, gender, marriage market.

DARIA Zinchenko (dzinchenko@hse.ru), NATIONAL RESEARCH UnIVERSiTy HighER SCHOOL OF ECONOMICS, RUSSIA.

THE REPORTED STUDY WAS FUNDED BY RFBR, PROJECT NUMBER 19-310-90071.

DATE RECEIVED : JULY 2021.

\section{REFERENCES}

Abramitzky R., Delavande A., Vasconcelos L. (2011). Marrying up: the role of sex ratio in assortative matching. American Economic Journal: Applied Economics, 3(3), 124-57.

Angrist J. (2002). How do sex ratios affect marriage and labor markets? Evidence from America's second generation. The Quarterly Journal of Economics, 117(3), 997-1038.

Banerjee A., Duflo E., Ghatak M., Lafortune J. (2013). Marry for what? Caste and mate selection in modern India. American Economic Journal: Microeconomics, 5(2), 33-72.

Becker G.S. (1973). A theory of marriage: Part I. Journal of Political Economy, 81(4), 813-846.

Becker G.S. (1974). A theory of marriage: Part II. Journal of Political Economy, 82(2, Part 2), 11-26.

Becker, G. S. (1991). A treatise on the family: Enlarged edition. Harvard university press.

Bertrand M., Cortés P., Olivetti C., Pan J. (2016). Social norms, labor market opportunities, and the marriage gap for skilled women (No. w22015). National Bureau of Economic Research. 
Bessudnov A.R., Kurakin D.Y., Malik V.M. (2017). Kak voznik i chto skryvaet mif o vseobshchem vysshem obrazovanii [The myth about universal higher education: Russia in the international context]. Voprosy obrazovaniya [Educational Studies Moscow], 3, 83-109. (In Russ.)

Blossfeld H.P., Timm A. (Eds.). (2003). Who marries whom?: educational systems as marriage markets in modern societies (Vol. 12). Springer Science \& Business Media.

Brainerd E. (2017). The lasting effect of sex ratio imbalance on marriage and family: Evidence from World War II in Russia. Review of Economics and Statistics, 99(2), 229-242.

Cherlin A.J. (2010). Demographic trends in the United States: A review of research in the 2000s. Journal of Marriage and Family, 72(3), 403-419.

Chiappori P.A., Iyigun M., Weiss Y. (2009). Investment in schooling and the marriage market. American Economic Review, 99(5), 1689-1713.

Darsky L.E., Ilyina I.P. (2000). Nekotoryye dannyye o sotsial'noy differentsiatsii brachnosti [Some evidence of social differentiation in marriage]. In A.G. Volkov (Ed.), Brachnost ${ }^{\prime} v$ Rossii. Analiz tablits brachnosti [Marriage rate in Russia. Analysis of nuptality tables] (pp. 44-46). Moscow: Informatika. (In Russ.)

De Hauw Y., Grow A., van Bavel J. (2017). The reversed gender gap in education and assortative mating in Europe. European Journal of Population, 33(4), 445-474.

Esteve A., García-Román J., Permanyer I. (2012). The gender-gap reversal in education and its effect on union formation: the end of hypergamy? Population and Development Review, 38(3), 535-546.

Esteve A., Schwartz C.R., van Bavel J., Permanyer I., Klesment M., Garcia J. (2016). The end of hypergamy: Global trends and implications. Population and Development Review, 42(4), 615.

Gihleb R., Lang K. (2020). Educational homogamy and assortative mating have not increased. Emerald Publishing Limited.

Goldin C., Katz L.F., Kuziemko I. (2006). The homecoming of American college women: The reversal of the college gender gap. Journal of Economic Perspectives, 20(4), 133-156.

Ilyina I.P. (1997). Vliyaniye voyn na brachnost' sovetskikh zhenshchin [Effect of wars on marriage rate of Soviet women]. In A.G. Vishnevsky (Ed.), Brachnost', rozhdayemost', smertnost' $v$ Rossii i v SSSR [Nuptiality, natality, mortality in Russia and in the USSR] (pp. 50-61). Moscow: Statistika Publ. (In Russ.)

Isen A., Stevenson B. (2010). Women's education and family behavior: Trends in marriage, divorce and fertility (No. w15725). National Bureau of Economic Research.

Itogi Vsesoyuznoy perepisi naseleniya 1989 g. (1989). Raspredeleniye naseleniya SSSR, RSFSR, eye avtonomnykh respublik, avtonomnykh oblastey i okrugov, krayev i oblastey po urovnyu obrazovaniya i vozrastu [Results of the All-Union Population Census of 1989. Educational level and age distribution in the population of the USSR, RSFSR, its autonomous republics, autonomous regions and districts, territories and regions]. Demoskop Weekly. Prilozheniya [Demoscope Weekly. Applications]. (In Russ.) URL: http://www.demoscope.ru/weekly/ssp/rus_edu_89.php?reg=2

Kalmijn M. (2013). The educational gradient in marriage: A comparison of 25 European countries. Demography, 50(4), 1499-1520. 
Lewis S.K., Oppenheimer V.K. (2000). Educational assortative mating across marriage markets: Nonhispanic whites in the United States. Demography, 37(1), 29-40.

Lichter D.T., Anderson R.N., Hayward, M.D. (1995). Marriage markets and marital choice. Journal of Family Issues, 16(4), 412-431.

Liu H., Lu J. (2006). Measuring the degree of assortative mating. Economics Letters, 92(3), 317322.

Mitrofanova E. (2019). Modeli vzrosleniya raznykh pokoleniy rossiyan [Models of the transition to adulthood of different Russian generations]. Demographic Review, 6(4), 53-82. (In Russ.)

Nielsen H.S., Svarer M. (2009). Educational homogamy how much is opportunities? Journal of Human Resources, 44(4), 1066-1086.

Oppenheimer V.K. (1988). A theory of marriage timing. American Journal of Sociology, 94(3), 563-591.

Oppenheimer V.K. (1997). Women's employment and the gain to marriage: The specialization and trading model. Annual Review of Sociology, 23(1), 431-453.

Perelli-Harris B., Lyons-Amos M. (2016). Partnership patterns in the United States and across Europe: the role of education and country context. Social Forces, 95(1), 251-282.

Roshchina Ya., Roshchin S. (2008). Brachnyj rynok v Rossii: vybor partnera i faktory uspekha [Marriage market in Russia: Choice of partner and success factors]. Matematicheskoe modelirovanie [Mathematical Models and Computer Simulations], 4, 21-37. (In Russ.)

Rosstat (2015). Mikroperepis' naseleniia 2015 g. [Census population of 2015]. Rosstat.

(In Russ.) URL: https://gks.ru/free_doc/new_site/population/demo/microperepis/finish/micro-perepis.html

Schofer E., Meyer J.W. (2005). The worldwide expansion of higher education in the twentieth century. American Sociological Review, 70(6), 898-920.

Schwartz C.R., Han H. (2014). The reversal of the gender gap in education and trends in marital dissolution. American Sociological Review, 79(4), 605-629.

Schwartz C.R., Mare R.D. (2005). Trends in educational assortative marriage from 1940 to 2003. Demography, 42(4), 621-646.

Van Bavel J., Schwartz C.R., Esteve A. (2018). The reversal of the gender gap in education and its consequences for family life. Annual Review of Sociology, 44, 341-360.

Volkov A.G. (1986). Semya - obekt demografii [Family is an object of demography]. M: Mysl'. (In Russ.)

Warner T.D., Manning W.D., Giordano P.C., Longmore M.A. (2011). Relationship formation and stability in emerging adulthood: Do sex ratios matter? Social Forces, 90(1), 269-295.

Zakharov S.V. (2013). Kuda dvizhetsia supruzhestvo v Rossii? [Where is marriage in Russia?]. Demoskop Weekly [Demoscope Weekly], 545-546. URL: http://demoscope.ru/weekly/2013/0545/tema06.php (In Russ.)

Zinchenko D., Lukiyanova A. (2018). Educational Assortative Mating and Income Inequality. HSE Economic Journal, 22(2), 169-196. (In Russ.)

Zinchenko D., Lukyanova A. (2021). Trends in Educational Assortative Mating in Russia: Do Changes in Educational Structure Matter? Universe of Russia, 30(1), 111-133. (In Russ.) 